\title{
Sociotechnical System Analysis for Identification of the Informational Requirements of Prosthetic Device Users for Upper Limb
}

\author{
Ian Hudson MOGGIO a, c, Maria Lucia Miyake OKUMURA ${ }^{\text {a,b }}$, \\ Geane Aparecida POTERIKO DA SILVA ${ }^{\mathrm{d}}$, Osiris \\ CANCIGLIERI JUNIOR ${ }^{\mathrm{a}, \mathrm{b}, 1}$ \\ a Pontifical Catholic University of Paraná - Polytechnic School \\ ${ }^{b}$ Industrial and System Engineering Graduate Program - PPGEPS/PUCPR \\ c Paraná State School - CEP \\ ${ }^{d}$ Paraná State Department of Education - SEED/PR
}

\begin{abstract}
According to the World Health Organization, more than one billion people on the planet have a type of disability. In Brazil, it corresponds to twenty- four per cent of the population, which creates a high level of social impacts, psychological vulnerability and dependence on others. In this context, Assistive Technology, including prosthetic devices, it is a resource that can be used in order to reduce those vulnerability levels. However, the product market of Assistive Technology is still limited, the few available products present high cost - contradicting Brazil's high poverty levels, and the rates of dissatisfaction and abandonment of those products are quite high since these people have many specificities. Considering these aspects, the Integrated Product Development Process (IPDP) for Assistive Technology arises as a solution to design products that can match the expectations of the users. The main purpose is to present a fraction of the IPDP of a prosthetic device for the upper limb. It is a research of Informational Design which is applied tools of ergonomics and universal design. In the methodology, the social context of people with upper limb disability was investigated applying tools of Macroergonomics, such as Socio-technical System analysis to reach the personal context of users of prosthetic devices. Then, the Likert tool was applied to the collected data. In the results, the user's specificities were found in order to use them to the product's requirements, which ones can contribute to the design of the product. It is concluded that the tools of product development, ergonomics, Universal Design and sociotechnical system analysis have applicability in the IPDP since they enable us to study the specificities of users in order to apply them in subsequent phases of IPDP with the approach in Design for Assistive Technology which contribute to product safety and quality.
\end{abstract}

Keywords. Design for Assistive Technology; Prosthetic Device, Integrated Product Development Process; Macroergonomics, Socio-technical System

\section{Introduction}

The World Health Organization (WHO) claims that physical, cognitive and sensorial disabilities affect more than one billion of people in the world and about one hundred and ten million of them have significative functional impairments that may limit the performance of daily activities and diminish social and economic participation in

\footnotetext{
${ }^{1}$ Corresponding Author, Mail: osiris.canciglieri@pucpr.br
} 
comparison to people without disabilities [1]. In Brazil, about $24 \%$ of the population presents at least one type of disability [2]. This situation creates high rates of physical, sensory or cognitive limitation. Besides that, it is an underdeveloped nation highlighting the situation of poverty and cases of social vulnerability of the population [3], in which many no longer have access to support products of assistive technology. Besides, the select group of individuals who manage to acquire have high levels of dissatisfaction and abandonment of assistive technology (AT) equipment, considering that the PwD has personalized specificities and requirements [4].

Through the use of Assistive Technology, it is possible to realize activities promoting quality of life and independence of PwD [4,5]. These AT products or services contribute to the expansion of physical and functional abilities and collaborate with autonomy development of PwD, reducing the social vulnerability rates. Among them, there are the prosthetic devices, the object of this study.

Companies in the AT market must pay attention to the topics mentioned before in order to achieve success in product development [6,7]. Thus, the corporations that use design tools during the development of manufacturing are highly competitive in the market. One of them is the Integrated Product Development Process (IPDP) [4]. IPDP is a set of approaches, methodologies and tools that aim to achieve the development of a product or service of quality in the shortest time possible, considering the necessities of the market, specifications of the project and technological possibilities [8].

This design tool can be divided into phases. One of them is the Informational Design which is responsible for extracting the user's requirements in order to convert them into AT product exigencies $[8,9,10]$. In this stage, several methodologies and resources can be used, such as tools of macroergonomics, a transdisciplinary approach $[11,12]$. One of those tools is the sociotechnical system analysis. The sociotechnical system was applied in this study aiming to comprehend human interactions with AT devices in order to find the users' specific data [13].

Furthermore, IPDP presents two factors that guarantee to develop a product of higher quality with a greater value for the user; therefore, with a minimum level of rejection. They are a) the possibility of including numerous professionals from different areas during the project planning who develop tests, studies, clinical trials, research and applications simultaneously, involving teams with interdisciplinary practice, considering that involves data exchanging in order to develop the product $[11,12]$ and; b) enabling simultaneous application of each phase of the IPDP [8]. The effective application of these two points allows a process of transdisciplinarity during the development of a product [14].

The main objective of this study is to present a fraction of Integrated Product Development Process (IPDP), in which macroergonomics tools are applied with an emphasis on the analysis of a sociotechnical system, Universal Design, Usability in an integrated process of transdisciplinary design. The research was limited to the phase of Informational Design geared towards Conceptual Design of a prosthetic support device for upper limb oriented to daily activities. For this, a bibliography review on the main themes of the study was carried out, followed by a survey through observational and exploratory research in public events where users of assistive technology products participate. Posteriorly, a survey was realized with the data from a sociotechnical system of a group compounded by one hundred and thirty users of prosthetic devices for upper limb, applied by an institution which is a support network for the person with physical disability of limb agenesis. Based on the investigation, a Likert tool [15] was used for data analysis. Finally, in the analysis of the results, the users' specificities have been 
identified and directed to the products' requirement and are presented in the conclusion of the research.

\section{Background}

\subsection{Assistive Technology User: person with agenesis of the upper limb}

In Brazil, PwD totalizes almost a quarter of the population, approximately 45,6 million people. Of these, people with physical disability sum $7 \%$ of the Brazilian population, representing about 13,4 million people [2]. Among this disability, there is a group of people with limb agenesis [17]. It is registered, per year, only in Brazilian territory, almost 50 thousand cases. The target audiences of the product development process that this research belongs are:

a) people with upper limb agenesis - concerning congenital malformations, deformities and chromosomal abnormalities during the gestation period and that resulted in the total or partial loss of the upper limbs [18], representing about 202 cases per year in the country [19];

b) population who, by consequence of an accident, trauma or illness, has had their arms, fingers or hands amputated, especially in traffic accidents $[18,19]$. In the case a, this type of disability affects over two per cent of born-alive children, and a tenth of them in upper's limbs [20].

These individuals pass through daily challenges to be able to perform everyday tasks, such as eating and dressing alone [21]. The area of human knowledge that holds the resources to develop functional skills of $\mathrm{PwD}$, Assistive Technology [5], presents prosthesis of upper limbs, as an alternative solution to these individuals in order to reduce physical limitations and assist in daily life activities [22].

However, despite technological advances, it is still a challenge to develop them in ways that meet the real needs of the users. Thus, some prosthesis of the market does not establish a process of rehabilitation based on these products; therefore, without improving people's quality of life. Consequently, there is a high rate of prosthesis abandonment [6,21].

However the usage of a prosthetic device for the upper limb with the accompaniment of a rehabilitation program provides $[9,19,23,24]$ : a) reduction of muscular dystrophy of the upper limb with agenesis; b) bilaterality exercises; c) strengthening and flexibility in the articulation of the limbs; d) preparation for future definitive prosthetization; c) prevention of scoliosis in adulthood. Finally, the prosthetic device contributes to the autonomy and independence of the person with disability and promotes social inclusion.

\subsection{Integrated Product Development Process and Design for Assistive Technology}

Engineering continually evolves in the area of Product Development Process. In the 1980 s, out of the need to reduce the time for the development of manufacturing and the necessity to understand the new profile of the user, companies developed approaches to conducting faster and more efficient processes. That way, in Concurrent Engineering environments, it reduces the distance between design and manufacture, through tools such as Design for Manufacturing and Design for Assembly, reducing deadlines in product development [25]. 
IPDP starts from the same legacy in Concurrent Engineering, the parallelism of tasks and presents two factors that strengthen the success of a product: a) the perception more focused on the user and b) transdisciplinarity [8]. The first one avoids professionals to weave a biased idea and guarantee the pleasantness of the users. Thus, from the understanding of the real users' needs, a product that responds directly to the needs of the market is developed $[8,26]$. Given the collaboration of professionals from different areas, it results in a transdisciplinary and integrated knowledge to develop the IPDP of Assistive Technology. In this way, it is possible to execute the stages of the process more assertively and to develop solutions that are required, considering the insertion of methodologies, approaches and tools from other areas in Engineering and integrating all knowledge of human science, such as macroergonomics.

That approach, the IPDP, is divided into phases. One of them is Informational Design. This phase is responsible for identifying the requirements, specificities and real needs of the users for whom the final product is intended for later converting them into product requirements. In this phase, Design for Assistive Technology [4] is approached, which involves Universal Design - which is a procedure of develop products and services that understood and can be used to the greatest extent possible by all users regardless of their age, size, ability or disability, not taking risks for them [27] -, Usability, Ergonomics and pleasantness for the three groups of users: a) primary: one who has direct contact with the product; b) secondary: a person with direct contact with the primary user and; c) tertiary: a professional who performs maintenance, assembly, confection and product indication services, such as physiotherapists, technicians and occupational therapists [4]. In this research, the three groups of users were considered, in order to enable multidisciplinary knowledge with a transdisciplinary process. In this way, considering the assistive technology users and the understanding their specifities, it is possible to create a device, which is directed to their needs and capabilities of them, aiming maximizes the functionality and increasing their social participation [28].

\subsection{Transdisciplinarity and Macroergonomics: Socio-technical System}

Ergonomics encompasses studies on the interactions between human beings and other elements or systems, so any research in this area must involve the human being and its interaction in a specific context of activity to carry it out.

"The ergonomists are responsible to planning, designing and evaluate tasks, work stations, products, places and systems in order to become them compatible with the specificities and the limitations of the users" $[12,13,28]$. Their activities can fluctuate in areas as health care, security, products design or work design.

In order to do those activities, the ergonomists have in-depth knowledge in many sciences, such as anthropometry, biomechanics, anatomic, human physiology, psychology, engineering and any area that can be necessary to know. Therefore, the ergonomics is about a transdisciplinary approach, considering it aims to resolve the problem of a world based on an academic experience or not, gettering the knowledge in order to propose solutions. That means, it transcends the approach of each discipline, and it urges throughout a single approach that can provide a new vision of nature and the reality $[11,12]$. It is about to establish a unique methodology. For that, each professional must not work in a targeted way as a multidisciplinary approach but must contribute proactively in front of an issue.

The object of the ergonomics, the work, is not only physiological or biomechanical. It synthesizes all those areas in order to make it more effective, comfortable and secure, 
which means that the solutions must be proposed considering all those areas. That is why ergonomics is a transdisciplinary approach [11,12,28].

Among the tools of ergonomics, there is the analysis of the sociotechnical system, which verifies the set of personal, technological, organizational subsystems and the internal and external environment directed towards macroergonomics [30].

Regarding the differences and specificities of the prosthetic device users, considering the poverty and vulnerability levels of Brazil and the background of the PwD, the technical solution to be adopted must consider the human factors and the transdisciplinarity in the problem. Thus, it was chosen the Sociotechnical system analysis. Analysis of the user's sociotechnical model takes into account an ergonomic approach, considering physical, psychological, social aspects of users crossing this information with the product's interaction data, in order to optimize human well-being and analyze the user specifics $[10,11,13]$. Adopting a sociotechnical approach to product development leads to a product that can be more acceptable to end-users and deliver better value to the final design [31].

\section{Methodology}

It is an applied nature research methodology, as it aims to generate knowledge for the understanding and practical application of a phenomenon. The research approach is quali-quantitative with an exploratory and observatory purpose, as it seeks to describe and investigate the phenomena of reality and to transform qualitative information into quantitative, as different areas of study were involved and that complement and express the research scenario. The technical procedures followed the stages of research methodology, as follows: a) To constitute the bibliographic review based on the concepts and tools of IPDP, Assistive Technology, Universal Design, Ergonomics, sociotechnical system involving the Social, Cultural, Physical, Psychological and Rehabilitation areas of users; b) Conduct exploratory research, with an observational basis, in the field, in order to understand the context of AT users. In this stage, seven events opened for publicoriented for PwD were attended by a transdisciplinary crew, including ergonomists, engineers, nurses and physiotherapists. In these events, over two thousand PwD was gettered; c) Elaborate and apply the questionnaire of social-technical analysis based on the observational research in the field and the bibliographic review. The application of this questionnaire was carried out by health professionals at a non-profit institution, who were physiotherapists, social workers, psychologists and occupational therapists. The institution is a support network for people with physical disabilities of agenesis and malformation of members and has a partnership term with the Research Center of Higher Education Institution. The questionnaire was applied to one hundred and thirty users who had direct or indirect contact with prosthetic devices for more than a year to participate in the research. The questions involved social, physical and psychological characteristics: gender, age, the region of residence, family income, education and the relationship with the devices. In addition, variants to be considered in the study of ergonomics such as use factor, safety, pleasantness and reliability of a device were measured and defined. In order to provide real statistics and make the research stronger, the Likert scale was used to analyze data on the personal importance of each requirement. This tool provides a better level of evidence and guarantees the findings; d) Analyze the data collected, from the crossing of information and constituting the Informational 
Design structure and direction to the Conceptual Product Design in the structure of the Design for Assistive Technology.

\section{Analysis of Results and Discussions}

\subsection{Assistive Technology Users in the field}

Observational-based exploratory research took place at seven events open to the public and aimed at PwD. Simultaneously, the AT market and the use of prosthetic support devices for upper limbs in social internet networks were explored. In the public events attended, it was observed that each group of people with disabilities uses resources or adapts, according to their specificities, to everyday situations, using specific skills. This stage was important for understanding the visible specificities of PwD.

\subsection{Analysis of the sociotechnical system}

The analyzes of the social-technical system considered the following variants, illustrated in Figure 1, which exemplifies the answers:
(A) Do not harm the skin
(F) Low cost
(B) Provide security
(G) Good appearance
(C) Easy to wear
(H) Size adjustment
(J) Do not require to use another product
(D) Easy to clean
(I) Do not cause pain
(K) Low volume
(E) Be light or discomfort
(L) Be discreet
(M) Facilitate to handle things

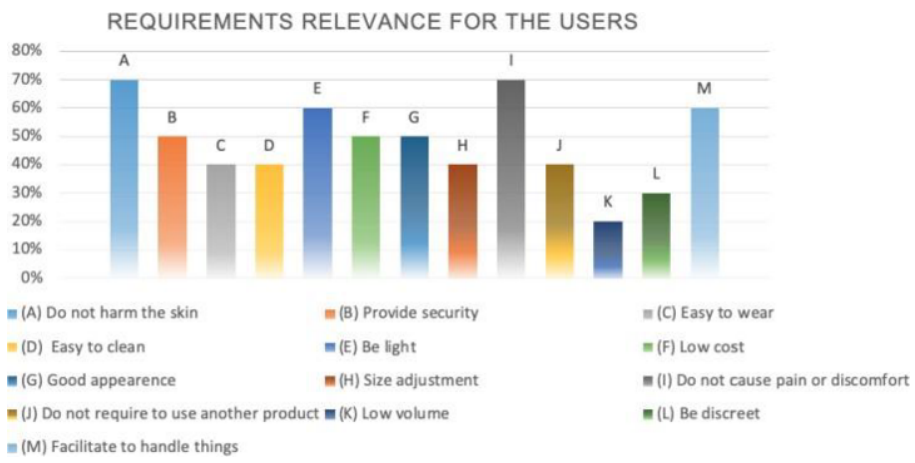

Figure 1. The scale of requirements for the user.

Besides, there was a field to specify points that were not suggested. In this data collection, it was noticed that most users who participated were women ( 81 users). In addition, most were over 30 years old (113 users), received between one and two minimum wages ( 98 users) and had a high school level (49 users). Regarding the variants, it was stipulated that would be considered only those that $50 \%$ or more of the individuals indicated a maximum degree of importance. Therefore, the requirements (C), (D), (H), $(\mathrm{J}),(\mathrm{K})$ and $(\mathrm{L})$ were disregarded. In the optional field, users pointed out the items "can be customized" and "presents easy maintenance", totalizing nine influencing factors of which the device accomplished eight and failed in one: (B) provide security, as it did not have an anchorage fixed on the user's body. 


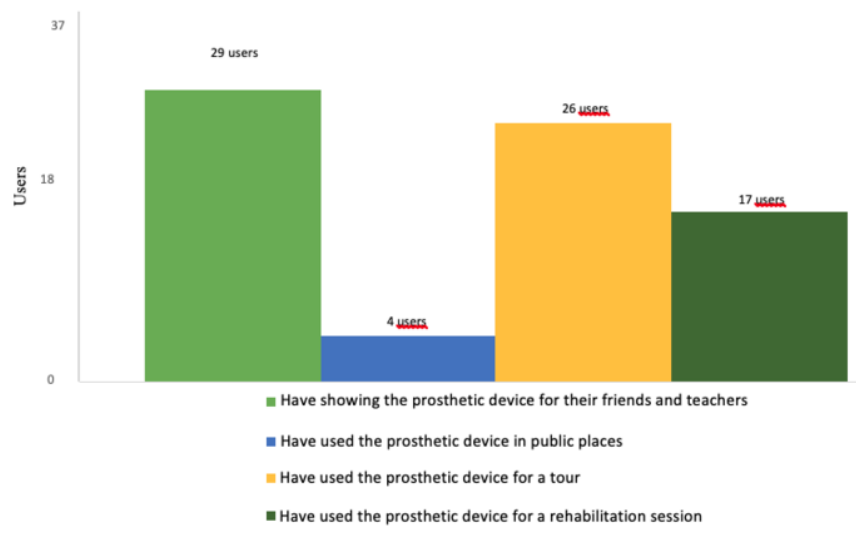

Figure 2. The behaviour of prosthetic device users.

Besides, it was made another data collection in a fraction of those users. This time, it was analyzed the behaviour of them - including adults and children that used a prosthetic device for at least a year, in front of daily events in a group of thirty-seven people. The Figure 2 illustrates the graphic of the behaviour of prosthetic device users given by the rehabilitation team, psychological and educational follow up, which belong to the board of professional volunteers from de association. They present the following aspects: a) most of the children who received the prosthetic support device took it to the classroom (29 users); b) adults prefer to use it without exposing. Only 4 users used in a public environment; c) 26 users used the device at least once in the external environment; d) 17 users used in rehabilitation sessions. The behaviour of the users identifies that there is greater motivation to use the prosthetic device among children who are encouraged by the parents and colleagues in the school environment.

Table 1. Results from the analysis of the user's requirements.

\begin{tabular}{lll}
\hline \multicolumn{1}{c}{ Universal Design Principles } & $\begin{array}{c}\text { Does the device offer } \\
\text { the principle? }\end{array}$ & Additions \\
\hline Principle 1: Equitable use & It does not & It should offer an operation indication \\
\hline Principle 2: Flexibility in use & It does & It works just flexing the elbow \\
\hline $\begin{array}{l}\text { Principle 3: Simple and intuitive } \\
\text { use }\end{array}$ & It does & It works just flexing the elbow \\
\hline $\begin{array}{l}\text { Principle 4: Perceptible } \\
\text { Information }\end{array}$ & It does & $\begin{array}{c}\text { The expectations were wearing it and } \\
\text { flexing the elbow }\end{array}$ \\
\hline Principle 5: Tolerance for error & It does not & It does not offer a signal for incorrect use \\
\hline Principle 6: Low Physical Effort & It does & It works just flexing the elbow \\
\hline $\begin{array}{l}\text { Principle 7: Size and Space for } \\
\text { Approach and Use }\end{array}$ & It does not & It does not need much effort to work
\end{tabular}

\begin{tabular}{lclll}
\hline \multicolumn{2}{c}{ Usability Principles } & $\begin{array}{c}\text { Does the device offer } \\
\text { the principle? }\end{array}$ & Additions \\
\hline $\begin{array}{l}\text { The products must be } \\
\text { predictable }\end{array}$ & It does & $\begin{array}{l}\text { The product is made using } \\
\text { parametrization }\end{array}$ & user \\
\hline $\begin{array}{l}\text { The results of any action must } \\
\text { match with the expectations }\end{array}$ & It does & $\begin{array}{l}\text { The expectations were open and close the } \\
\text { hand }\end{array}$
\end{tabular}




\begin{tabular}{|c|c|c|}
\hline $\begin{array}{l}\text { It must be positive learning } \\
\text { sharing }\end{array}$ & It does & $\begin{array}{l}\text { The user receives rehabilitation sessions in } \\
\text { the beginning }\end{array}$ \\
\hline $\begin{array}{l}\text { It must respect the human } \\
\text { variability }\end{array}$ & It does & $\begin{array}{l}\text { The product is made using user } \\
\text { parametrization }\end{array}$ \\
\hline It must prevent mistakes & It does & $\begin{array}{l}\text { The device stops to work, needing a } \\
\text { maintenance }\end{array}$ \\
\hline It must feedback & It does not & It could offer a sound reply \\
\hline $\begin{array}{c}\text { Users } \\
\text { Principles }\end{array}$ & $\begin{array}{l}\text { Does the device offer } \\
\text { the principle? }\end{array}$ & Additions \\
\hline A. Does not harm the skin? & It does & The device is tied with confortable fabrics \\
\hline B. Provides security & It does & The device works tied to the user \\
\hline E. Be light & It does & It is made by plastic \\
\hline F. Low cost & It does & It has a low price \\
\hline G. Good apparance & It does & It offers simples and discreets lines \\
\hline I. Does not generate pain & It does & The device is tied with confortable fabrics \\
\hline M. Facilitate to handle things & It does & It helps to daily actions, such as to eat \\
\hline $\begin{array}{l}\text { N. Offer to be customizes (for the } \\
\text { users) }\end{array}$ & It does & $\begin{array}{l}\text { In the manufacturing, the } 3 \mathrm{D} \text { printer can } \\
\text { create anu customization }\end{array}$ \\
\hline $\begin{array}{l}\text { O. Offer easy maintenance (for the } \\
\text { users) }\end{array}$ & It does & $\begin{array}{l}\text { In the Design is applied tools of Design for } \\
\text { Assembly }\end{array}$ \\
\hline
\end{tabular}

Thus, from the analysis of the variants and the exploratory research on the use of the prosthetic device, a survey was carried out considering the principles of Universal Design, together with Usability and user's behaviour. Table 1 shows that 17 from the 22 requirements were met, corresponding to $77 \%$. However, the requirements that did not match the principles were those that did not apply to the analysis of the prosthetic device of the upper limb, such as Principle 1 of "Equitable". Also, the Principle 7, "Size and Space use" of Universal Design, which is intended only for a person with limb agenesis and uses only on the side of the amputation was not considered. And, for the same reason, the Usability Principles to prevent errors of use or to issue a usage alert, had been disregarded. From the data collection, the phase of Informational Design was constituted. That one is responsible for the concept the forms, lines, functions, materials and experiences of the final product being reported on another fraction of the research. Nowadays, this prosthetic device is on the feedback phase, as Figure 3 shows.

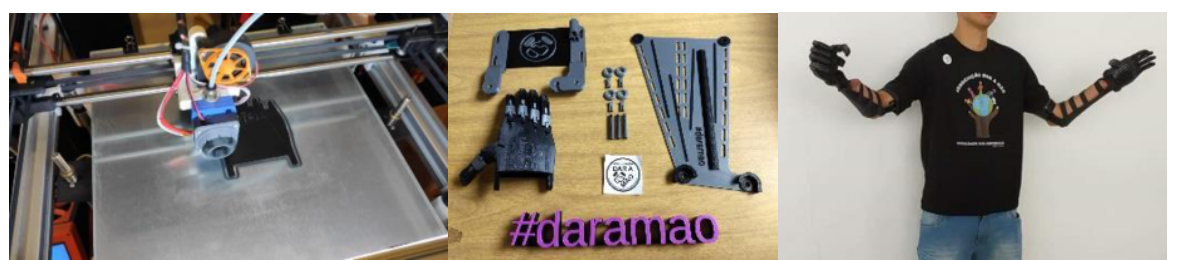

Figure 3. The Prosthetic device for upper-limb agenesis.

\section{Conclusion}

In this research, the approaches of Universal Design, Usability and Ergonomics, as well as sociotechnical analysis, have practical applicability within the Product Development Process-oriented to Assistive Technology for the Informational Design phase. The research involving the sociotechnical system was carried out for primary, secondary and tertiary users of upper limb prosthetic devices, who were mostly located in urban and metropolitan regions with the level of education above high school. It should be noted that professionals qualified in the areas of health, pedagogy, rehabilitation an 
engineering participated as tertiary users, who have higher education and reflected in the results of the sociotechnical analysis, providing different multidisciplinary expectations and in the analysis of transdisciplinary processes. According to the collaborating institution, only those who have access to the internet network participated, noting that most of their registered associates contact only via mobile device with limited access. Therefore, the family income and education variations show a sample of users with access to information and greater interaction with the community of users of prosthetic devices.

These results were transferred to the IPDP Conceptual Design phase to define the structure of the prosthetic device, and then to the Detailed Design. In this way, there is the comprehension of the processes involved in the ability to analyze biomechanical movements, psychological aspects, safety and the possible bodily consequences resulting from the interaction of the human body with the environment.

In this study, the tools used to demonstrate that the product meets almost all requirements, except those that have indirect influences or were not part of the users' context. However, the deepening in the tools of macroergonomics applied in Design for Assistive Technology, identify requirements that interfere in the functionality of the product to adjust in the final prototype.

In the survey of the user's behaviour, it was found that it needs greater encouragement and awareness to participate in rehabilitation programs, which reflects in better performance and quality of life with the proper use of the prosthetic device.

In addition, this research seeks to develop lower-cost product designs, corresponding to the user's expectations. Thus, alternative materials are sought that correspond to the users' expected quality and contribute to the advance of technology to meet the areas of diversity and accessibility.

\section{Acknowledgement}

The authors thank the Pontifical Catholic University of Parana and the Brazilian National Council for Scientific and Technological Development (CNPq) for financial support and Dar a Mão Association for partnership in this research.

\section{References}

[1] World Health Organization (WHO), World Report on Disability. [Online]. Available: https://www.who.int/disabilities/world_report/2011/en

[2] Instituto Brasileiro de Geografia e Estatística (IBGE), Censo Demográfico 2010: Características gerais da população, religião e pessoas com deficiência, IBGE, R. Janeiro, 2012, pp.1-215.

[3] G. Mcgimpsey, T. Bradford, Limb Prosthetics Services and Devices Critical Unmet Need: Market Analysis - White Paper, Bioengineering Institute Center for Neuroprosthetics, Worcester Polytechnic Institution Worcester, Massachusettes, 2015.

[4] M.L.M. Okumura, Conceptual Model of Design Oriented to Assistive Technology-MPOTA, doctoral thesis, Industrial and Systems Engineering Graduate Program, PPGPS/PUCPR, Curitiba (PR), 2017.

[5] H. Burger, Can the international classification of functioning, disability and health (ICF) be used in a prosthetics and orthotics outpatient clinic? Prosthet Orthot Int., vol 35(3), 2011.

[6] V.C.S. Lazoski, Determinação dos requisitos do usuário para o suporte ao desenvolvimento integrado de produto orientado à proteses de membros superiores, dissertation of Master, Industrial and Systems Engineering Graduate Program, PPGEPS/PUCPR, Curitiba (PR), 2018.

[7] A.F. Newell, P. Gregor, M.E. Morgan, C. Macaulay, User-Sensitive Inclusive Design, Universal Access Information Society, 2011, 10(1), 235-243. Available: https://doi.org/10.1007/s10209-010-0203-y 
[8] N. Back, A. Ogliari, J.da Silva, A. Dias, Projeto integrado de produtos: planejamento, concepção e modelagem, Manole, Barueri (SP), 2008.

[9] M.L.M. Okumura, O. Canciglieri Junior, Modelo conceitual de projeto orientado para tecnologia assistiva: Design de tecnologia assistiva - DFAT, NEA, OmniScriptum Publishing, Mauritius, 2018.

[10] I.H. Moggio, M.L.M. Okumura, O. Canciglieri Junior, Análise sociotécnica com enfoque macroergonômico para desenvolvimento de dispositivo de apoio protético, Paes, V.C, (org.), Coletânea Brasileira de Engenharia de Produção, Stellata Editora, Itajubá (MG), 2020, pp. 292-307.

[11] N. Almeida Filho, Transdisciplinarity and the Post-Disciplinary Paradigm in Health, Saúde e Sociedade, São Paulo, 2005, pp.30-50.

[12] International Ergonomics Association-IEA. Ergonomics International News and Information, Marshall Associates, London, 2000.

[13] I. Ilda, L.B.M. Guimaraes, Ergonomia: Projeto e Produção, 3 ed, Blucher, São Paulo, 2016.

[14] J.P. Terpenny, R.M. Golf, M.R. Vernon, W.R. Green, Utilizing assistive technology design projects and interdisciplinary teams to foster inquiry and learning in engineering design, International Journal of Engineering Education, 2006, vol 22(3), pp. 609-616.

[15] R. Likert, A technique for the measurement of attitudes, Archives of Psychology, New York University, New York, 1932, vol 22(140).

[16] United Nations, enable, The invisibility of disability, infographics, 2015. Available: http://www.un.org/disabilities/documents/sdgs/infographic_statistics_2016.pdf, Accessed: May, 152020.

[17] F.J. Kottke, G. Stillwell, J.F. Lehmann, Krusen: Tratado de Medicina Física e Reabilitação, 3 ed, Editora Manole, São Paulo, 1984.

[18] Brasil, Decreto Lei n 5296/2004: Promoção da acessibilidade das pessoas portadoras de deficiência ou com mobilidade reduzida, Casa Civil da Presidência da República, Brasília, 2004.

[19] Brasil, Ministério da Saúde, Secretaria de Atenção à Saúde, Departamento de Ações Programáticas Estratégicas, Diretrizes de atenção à pessoa amputada, 1. ed. 1. reimp. Ministério da Saúde, Brasília, 2013.

[20] E. N. França Bisneto, Deformidades congênitas dos membros superiores. Parte I: Falhas de formação. Revista Brasileira de Ortopedia, 2012;47(5):545-52.

[21] F. Cordella, A.L.Ciancio, R. Sacchetti, A. Davalli, A.G. Cutti, E. Guglielmelli, L. Zollo, Literature Review on Needs of Upper Limb Prosthesis Users, Frontiers In Neuroscience, 2016, https://www.frontiersin.org/articles/10.3389/fnins.2016.00209/full, Accessed: May, 152020.

[22] P. C. Hein, J. L. Cassidy, C. Bodine, The Rehabilitation Engineering Research Center for the Advancement of Cognitive Technologies, American Journal of Alzheimer's Disease Other Dementias, 2015, Vol 30(1), pp.612.

[23] World Health Organization - WHO, The Rehabilitation of People With Amputations, World Health Organization United States Department of Defense MossRehab Amputee Rehabilitation Program MossRehab Hospital, USA, 2004.

[24] A. C. Ramos, I. S. Sales, Amputações de membros superiores, Terapia Ocupacional na reabilitação Física, Roca, São Paulo, 2003.

[25] G.D. Cunha, A Evolução dos Modos de Gestão do Desenvolvimento de Produtos, Produto\&Produção, Pontifícia Universidade Católica do Rio Grande do Sul, Departamento de Engenharia de Produção, RGS, 2008.

[26] C.H. Wang, R.C.C. Chen, A MPCDM-enabled Product Concept Design via User Involvement Approach, Concurrent engineering: Research and Applications, 2011, Vol. 19(1), pp. 19-34.

[27] L. R. Mace, J. G. Hardie, P. J. Place, Accessible Environment: Toward Universal Design, 1 ed, Van Nostral Reinhold, New York, 1991.

[28] IEA (International Ergonomics Association), The Discipline of Ergonomics, 2000. Available: www.iea.cc. [29] C. C. Nielsen, M. Jorge, M. Orthotics and Prosthetics in Rehabilitation: Multidisciplinary Approach, In:

M.M. Lusardi, M. Jorge, C.C. Nielsen, Orthotics \& Prosthetics in Rehabilitation, 3 ed., Elsevier Saunders, Missouri, 2013, pp. 1-13.

[30] R.S. Bitencourt, M.L.M. Okumura, L. B. M. Guimarães, M. G. Derenevich, O.Canciglieri Junior, Ergonomia: uma proposta de representação no design gráfico ergonomia, ABERGO 2019 XIX Congresso Brasileiro de Ergonomia, Rio de Janeiro, ABERGO, 2019, pp.1-10.

[31] I. G. Branco. A. C. Santos, Socio-Technical System Design to Offer Specialty Coffee Ready for Consumption, Advances in Transdisciplinary Engineering, Vol. 2, pp. 216-225.

[32] L.B.M. Guimarães, J.L.D. Ribeiro, R.S. Bitencourt, I. Iida, Investigation of the Brazilian academic production in Ergonomics, from 1987 to 2017, Production, São Paulo, 2019, Vol. 29, pp.1-14. 